Association for Information Systems AIS Electronic Library (AISeL)

AMCIS 2000 Proceedings

Americas Conference on Information Systems

(AMCIS)

2000

\title{
Studies of ALN: An Empirical Assessment
}

David Spencer

New Jersey Institute of Technology, dspencer@pegasus.rutgers.edu

Starr Roxanne Hiltz

New Jersey Institute of Technology, roxanne.hiltz@gmail.com

Follow this and additional works at: http://aisel.aisnet.org/amcis2000

\section{Recommended Citation}

Spencer, David and Hiltz, Starr Roxanne, "Studies of ALN: An Empirical Assessment" (2000). AMCIS 2000 Proceedings. 354.

http://aisel.aisnet.org/amcis2000/354

This material is brought to you by the Americas Conference on Information Systems (AMCIS) at AIS Electronic Library (AISeL). It has been accepted for inclusion in AMCIS 2000 Proceedings by an authorized administrator of AIS Electronic Library (AISeL). For more information, please contact elibrary@aisnet.org. 


\title{
Studies of ALN: An Empirical Assessment
}

\author{
David Spencer, Rutgers University, dspencer@pegasus.rutgers.edu \\ Starr Roxanne Hiltz, New Jersey Institute of Technology, roxanne@adm.njit.edu
}

\begin{abstract}
This analysis of the research literature seeks to gain insight into the study of effectiveness of Asynchronous Learning Networks (ALN). A database of material gathered from the papers reporting the studies is described. The current picture of that data is highlighted and discussed. Additional papers are expected to be supportive of a need for better research techniques in the ALN community.
\end{abstract}

\section{Introduction}

This review of 30 empirical studies of Asynchronous Learning Networks (ALN) is intended to provide a snapshot of how case and field studies are being carried out and what findings are more than singular. This study is a parallel with an earlier assessment of studies of group support systems. (Fjermestad and Hiltz, 2000)

The terminology of ALN was coined by the Sloan Foundation to distinguish anytime/anyplace computermediated communications (CMC), such as bulletin boards and email, from same time versions of distance learning. Their definition: "Asynchronous Learning Networks (ALN) are people networks for anytime - anywhere learning. ALN combines self-study with substantial, rapid, asynchronous interactivity with others. In ALN learners use computer and communications technologies to work with remote learning resources, including coaches and other learners, but without the requirement to be online at the same time. The most common ALN communication tool is the World Wide Web." (http://www.aln.org/alnweb/aln.htm)

We searched the literature for empirical studies that were of ALN (asynchronous conferencing or email) and published in English language refereed journals or conference proceedings reporting some findings to a research question.

Though all studies of distance learning use students and teachers as subjects, they are usually not strictly experiments because they lack random assignment to treatment and have internal validity problems such as difficulty measuring outcomes by survey. However, they do have the advantage of good external validity and a large population from which to choose a sample. Many studies of distance learning have been reported, as computer networks become the medium of choice. A large proportion of them are classified as finding "no significant difference" in effectiveness as compared to traditional face-to-face learning. (Russell, 1999) This paper's studies, however, are aimed at comparing just one particular manifestation of distance learning, that is, asynchronous computer mediated classrooms, to traditional on campus classrooms.

\section{Framework}

The objective of this study of studies is to give a broad view of work being done in the field of $\mathrm{CMC}$ research as applied to distance learning through ALN. Our research questions are: (1) Can the results of studies of ALN be summarized or aggregated as provably significant? The use of ALN can be considered successful if ALN learning outcomes are equal to or better than traditional face-toface class outcomes. (2) How often has this comparison been made and if so what is the common result? (3) Have various means of delivering ALN been compared and to what extent do some means classification result in better outcomes than others? To give a framework to this research we looked for (and recorded) information in the reports such as:

- $\quad$ Context: class size, subject matter, M/F ratio, age of students and other data about the school and instructor are independent variables.

- Intervening factors: general classifications of media type, study method, and class organization are also considered independent variables.

- Research questions, including purpose of study, goals of the institution and hypotheses. These were sometimes hard to find but crucial to understanding the results of the study.

- $\quad$ Outcomes, stated either explicitly in quantitative terms or qualitative discourse in the judgment of the researcher, are considered the dependent variables. These were recorded in reference to the research question either stated or inferred.

\section{Method}

We were able to find these reports of studies by primarily using online search techniques. The refereed online journals were rich in reports of ALN studies, though not always providing enough information to use here. Much research is conducted in venues other than the standard sociology and information systems area but is usually too anecdotal to use here.

As we found the papers meeting the acceptance criteria (above), they were read for the information in our framework and that information was entered into a Microsoft Access database. This helped in being consistent in data collection and thorough in the first reading. The database also now is a ready source of data for insertion into a Microsoft Word report in either a 
complete listing or in summative form. Furthermore the coded data is readily available for statistical analysis. As more papers are added to the collection of this study their entry into the database will update the past reports and statistical data with little or no extra effort.

\section{Analysis}

Preliminary analysis reveals serious lack of good research reporting and thus suggests less than adequate research methods. Many studies did not report a research question and hypotheses in a clear and usable manner, though nineteen of the thirty, did highlight their intent, some even using the H\# convention. These hypotheses were recorded verbatim in the database. For the other eleven (37\%), we inferred the research question and generated hypotheses to match the reported results. This of course may lead to measurement error on the part of this study but seems unavoidable in the effort of aggregating disparate work.

Nineteen $(63 \%)$ of the papers reported case studies, the rest quasi-experiments. Experiments reported had a control group but did not have the opportunity to randomly assign subjects to treatment at either the student level or the class level. Distance learning students were by dint of location able to attend class only by online access. Most experiments using multiple classes were cross-sectional over one semester. Only one experiment compared classes longitudinally.

No two studies reported the same subject matter. There were a significant number (12) of studies of classes studying management information systems type subject matter such as technology, web development, etc. Many studies were of multiple classes of various subjects. This is a limitation of this study, as we cannot control for subject matter except at a large aggregate level.

Class size was reported in all but one study. The composition of individual classes was generally not reported however when multiple classes were studied. When multiple classes were studied the researchers generally did not consider the class as a unit of study, thus losing an opportunity to analyze groups as entities.

Student age and gender were only sporadically reported. Matriculation status could be categorized as undergraduate, masters, or postgraduate in most cases but several studies reported undergraduates of ages ranging from 18 to 40 years. Therefore student age seems not a definable factor. Gender ratio was reported in only six $(20 \%)$ of the studies leaving that factor also without sufficient data for this study.

ALN technology used was reported in detail in most papers. We also recorded use of synchronous media such as video conferencing, interactive TV, Chat, Video and Audio streaming. When the media was synchronous we noted if the class was held in a "same room" format. This might have been the case if the class was additionally expected to meet asynchronously via computer conference. Nineteen of the thirty studies reported the students were campus based and presumably could meet face-to-face. Only one study reported the use of asynchronous video and audio streaming such as recorded lectures.

\section{Outcomes}

As stated earlier, eleven of the studies did not state a research question or hypothesis to be tested. However these could be inferred from the author's discussion of the context and methods of study. In the six cases of explicit hypothesis statements the outcomes were also clearly stated in such a manner to support the author's conclusion.

We recorded the hypotheses and results verbatim in the case of explicit sources. We generated a short hypothesis for those lacking a concise statement of such and then paraphrased the authors' conclusions as results. For explicit reported results the detail was such that the reader could easily follow the author's conclusion and implications for theory building.

Given those skills of these researchers, the answer to our first research question is: Yes the results of the various studies can be aggregated into a provably significant summary.

It may come as no surprise that all studies report positive results, indicating either no significant difference or significant advantages of computer mediated distance learning over traditional face-to-face classroom teaching. That may be because there is an advantage to the use of computer mediation or it may be that papers don't get written about studies showing less advantages to ALN. So the answer to our second research question (how many studies?) is likely not answerable except in the sense that those studies reported do report positive results with enough detail to answer what works better.

The answer to the third research question is most definitely no. The various means of ALN have not been compared. This study may be able to do that by including more papers in the database. This study will continue to search for papers reporting results either way and to formalize the analysis of the aggregation of those papers.

\section{References:}

Fjermestad, J. and Hiltz; S.R., "Case and Field Studies of Group Support Systems: An Empirical Assessment"; Hawaii International Conference on System Sciences, 2000.

Russell, T., "The 'No Significant Difference Phenomenon"”, North Carolina State Univ., 1999, cuda.teleeducation.nb.ca/nosignificantdifference

A current list of papers comprising this study's database is available upon request. 